\title{
Letter to the Editor concerning "Comparison of blood loss according to use of aspirin in lumbar fusion patients" (by Park HJ, Kwon KY, Woo JH (2014) Eur Spine J. doi:10.1007/s00586-014-3294-y)
}

\author{
Liang Ding $\cdot$ Zhimin He $\cdot$ Haijun Xiao \\ Feng Xue
}

Received: 29 May 2014/Revised: 21 June 2014/Accepted: 21 June 2014/Published online: 28 June 2014

(c) Springer-Verlag Berlin Heidelberg 2014

\section{Dear Sir,}

We are writing to you to express our significant concerns about the methodology of one of the articles published in your online journal on April 17, 2014 titled: "Comparison of blood loss according to use of aspirin in lumbar fusion patients" [1]. The surgeons always must keep in mind of the excessive bleeding during or after the operation in patients who undergo lumbar decompression and fusion, because blood loss will increase the risk of resultant epidural hematoma that leads to neurologic demise. So the authors should be commended for an interesting collection of data for a difficult problem. Anything we can learn to decrease blood loss would be nice to know.

In previous reports, the common causes of blood loss in lumbar fusion are posterior vs. anterior approach, the use of instrumentation, multiple levels fused, male vs. female, younger age, body weight, aprotinin therapy, type of anesthesia, intra-abdominal pressure and high preoperative hemoglobin [2-4]. In this study, a total of 106 patients were divided into three groups. Their age, sex, weight, underlying diseases, non-steroidal anti-inflammatory drugs (NSAIDs) taken, operation time and preoperative platelet count $\left(/ \mathrm{mm}^{3}\right)$ were measured in all three groups to determine the difference in blood loss among the groups. But there is no mention about the number of levels fused and the approach of surgery in these patients. Were there all more than four segments of lumbar fusion surgery in Group 1, or all two segments in Group 3? Were there all anterior approach surgery in Group 1, or all posterior approach in Group 3? An increasing segment of fusion can significantly increase the risk of blood loss [2-4]. The approach of surgery was also correlated with blood loss. It may have an impact on the results and conclusions, if the segments of lumbar fusion as risk factor for blood loss were ignored in the study.

Conflict of interest None.

\section{References}

1. Park HJ, Kwon KY, Woo JH (2014) Comparison of blood loss according to use of aspirin in lumbar fusion patients. Eur Spine J. doi:10.1007/s00586-014-3294-y

2. Zheng F, Cammisa FP Jr, Sandhu HS, Girardi FP, Khan SN (2002) Factors predicting hospital stay, operative time, blood loss, and transfusion in patients undergoing revision posterior lumbar spine decompression, fusion, and segmental instrumentation. Spine (Phila Pa 1976) 27(8):818-824

3. Lentschener C, Cottin P, Bouaziz H, Mercier FJ, Wolf M, Aljabi Y, Boyer-Neumann C, Benhamou D (1999) Reduction of blood loss and transfusion requirement by aprotinin in posterior lumbar spine fusion. Anesth Analg 89(3):590-597

4. Johnson RG, Murphy M, Miller M (1989) Fusions and transfusions. An analysis of blood loss and autologous replacement during lumbar fusions. Spine (Phila Pa 1976) 14(4):358-362
L. Ding $\cdot$ Z. He $\cdot$ H. Xiao $\cdot$ F. Xue $(\bowtie)$

Department of Orthopaedics, Shanghai Fengxian Central

Hospital, Shanghai 201400, China

e-mail: xuefengky@163.com 